\title{
Substitutes for xylene in histopathology and the role of temperature
}

\author{
Gayathri $G^{1}$, Snegha $A^{2}$, Teleflo $B^{3}$ \\ ${ }^{1}$ Dr. Gayathri Ganesan, Assistant Professor, Department of Pathology, Kilpauk Medical College, Chennai, India, ${ }^{2}$ Dr. \\ Snegha Ananth, Medical student (MBBS), Kilpauk Medical College, ${ }^{3}$ Dr.Teleflo Boopathy, Assistant Professor, all \\ authors are affiliated with Kilpauk Medical College, Chennai, Tamil Nadu, India.
}

Address for Correspondence: Dr. Gayathri Ganesan, Assistant Professor, Department of Pathology, Kilpauk Medical College, Chennai, India. Email id: gg3doc84@gmail.com

\begin{abstract}
Background: Deparaffinization of wax sections in histopathology requires Xylene which is a harmful and toxic compound. It has been successfully replaced by many common household products such as dishwashing liquid, soaps and mineral oils. However, all these substitutes require higher temperatures of upto $90^{\circ} \mathrm{C}$ for effective deparaffinization. Aim: To evaluate the temperature dependent efficacy of dishwashing liquid in deparaffinization of histopathological sections as a substitute to the routine toxic Xylene. Method: 100 tissue sections deparaffinised by conventional Xylene and stained by Hematoxylin and Eosin method were objectively scored against 300 matched sections deparaffinised using dilute dishwashing liquid method at $65^{\circ} \mathrm{C} / 75^{\circ} \mathrm{C} / 90^{\circ} \mathrm{C}(100$ each) by a single blinded pathologist. Results: Based on Wilcoxon signed ranks test, at $90^{\circ} \mathrm{C}$ the Xylene free method stood on par with the conventional method $(\mathrm{p}=0.422$, $\mathrm{p}>0.05$ ) proving Xylene free sections were as good or better than the matching conventional sections in $76 \%$ of the comparisons. Xylene free sections at $65^{\circ} \mathrm{C}$ and $75^{\circ} \mathrm{C}$ were found to be inferior to the conventional method in $80 \%$ and $69 \%$ of the comparisons respectively and also statistically significant from the conventional method $(\mathrm{p}=0.002$ and 0.019 respectively). Conclusion: The new Xylene free method using dishwashing liquid is highly temperature sensitive and effective only at higher temperatures.
\end{abstract}

Keywords: Deparaffinization, Dishwashing liquid, Histopathology, Xylene, Temperature

\section{Introduction}

The backbone of daily histopathological diagnostic work is the paraffin section usually stained with Hematoxylin and Eosin. Paraffin sections are still prepared by methods largely unchanged for over 150 years. The process of deparaffinisation of the slides using Xylene is an important preliminary step before the staining process, which makes the tissue sections to uptake the Haemotxylin and Eosin stain properly. This makes Xylene an inevitable compound in histopathology due to its paraffin solvent action. However it is a toxic compound that is hazardous for human use and the environment in which it is disposed [1]. Therefore, any substitute that minimizes the use of Xylene in experiments, reduces tissue staining time and does not compromise its quality will be efficient for diagnostic reasons and valuable for maintaining a safe laboratory environment.

Manuscript received: $30^{\text {th }}$ July 2016 Reviewed: $08^{\text {th }}$ August 2016

Author Corrected: $19^{\text {th }}$ August 2016

Accepted for Publication: $28^{\text {th }}$ August 2016
The innovative concept of using dish washing liquid at $90^{\circ} \mathrm{C}$ to dewax tissue sections was first experimented by Falkeholm et al in 2001 [2]. Since then various laboratories have done pilot trials with successful outcomes.

However, the results of these trials were varied with regard to individual parameters like nuclear staining, cytoplasmic staining and clarity. There were also other substitutes that showed promising results like diluted lemon water, mineral oil and hot distilled water.

The common factor among all the substitutes was they had to be used at high temperature $\left(90^{\circ} \mathrm{C}\right)$ to be effective. The role of temperature is further favored by studies that showed promising results by substituting Xylene with hot plain distilled water and conducting the process in a microwave. Hence, we designed the experiment using dish washing solution as a substitute to Xylene at three different temperatures $65^{\circ} \mathrm{C}, 75^{\circ} \mathrm{C}$ and $90^{\circ} \mathrm{C}$ to implore the effect of temperature. 


\section{Materials and methods}

I. Preparation of $\mathbf{1 . 7 \%}$ Diluted liquid dish washing solution: $25 \mathrm{ml}$ of locally available 'Vim ${ }^{\circledR}$, dish washing solution $+1500 \mathrm{~mL}$ of distilled water [3].

This product contains sodium laureth sulphate, sodium dodecyl benzene sulphonate, cocamidopropylbetaine and nonionic surfactants. In our study we diluted $25 \mathrm{~mL}$ of dish washing solution with $1500 \mathrm{~mL}$ of distilled water which brings the level of these compounds well below their reported toxic levels. Additionally, their concentrations in the product are strictly monitored by the manufacturer.

The study group included tissues such as epithelium, connective tissue, glands, bone, muscle, and cartilage. Four sections of 4 microns each were cut from 100 paraffin embedded tissue blocks.

One section was deparaffinised with the conventional Xylene method and the other three with Xylene free method using $1.7 \%$ dish washing solution under different temperatures $65^{\circ} \mathrm{C}, 75^{\circ} \mathrm{C}$ and $90^{\circ} \mathrm{C}$. All the 4 deparaffinised sections were stained using conventional Hematoxylin and Eosin method.

\section{Preliminary tissue sectioning and paraffinization:}

1. Fixation: Square tissue blocks (about $1 \mathrm{~cm}$ in each dimension) are fixed by chemical fixation. The fixative used is a $4 \%$ aqueous solution of formaldehyde, at neutral $\mathrm{pH}$. The chemical added binds to and cross-links some proteins, and denatures other proteins through dehydration. This hardens the tissue, and inactivates enzymes that might otherwise degrade the tissue. Fixation also kills bacteria.

2. Dehydration and clearing: The tissue is embedded in paraffin wax, but wax is not soluble in water or alcohol. However, it is soluble in a paraffin solvent like Xylene. Therefore, the water in the tissue needs to be replaced with Xylene. To do this, first the tissue is dehydrated, by gradually replacing water in the sample with alcohol.

This is achieved by passing the tissue through increasing concentrations of ethyl alcohol (from $70 \%$ to $90 \%$ ). Finally, once the water has been replaced by $90 \%$ alcohol, the alcohol is replaced with Xylene, which is miscible with alcohol. This final step is called 'clearing'.

3. Embedding: The tissue is placed in warm paraffin wax, and the melted wax fills the spaces that used to have water in them. After cooling, the tissue hardens, and is cut into sections.

Upto this, the procedure is same for both the methods - conventional and Xylene free staining.

4. Sectioning: The tissue block is trimmed and mounted on the microtome. Thin sections of 4 microns are cut, which are deparaffinised, stained and mounted on a microscope slide.

5. Deparaffinisation, Staining and Mounting: Conventional $H \&$ E Method: Most staining solutions are aqueous, so to stain the sections, the wax is dissolved (deparaffinised) using Xylene and then replaced with water (rehydration). For this the sections are passed through decreasing strengths of alcohol (90\% to 70\%) and then stained with Haematoxylin and Eosin stains. Once stained, the section is then dehydrated once again, and placed in Xylene. It is then mounted using a mounting media and a coverslip is placed on top, to protect the sample.

Xylene Free Method: Deparaffinisation was carried out using the $1.7 \%$ diluted dish washing liquid at $65 / 75 / 90{ }^{\circ} \mathrm{C}$ instead of Xylene followed directly by Haematoxylin and Eosin staining. In this method the process of rehydration before staining and dehydration before mounting using graded alcohols also becomes unnecessary as suitable temperatures are employed. Staining follows immediately after deparaffinization.

Oven drying the Xylene alcohol free sections at $60^{\circ} \mathrm{C}$ prior to cover slipping are sufficient as depicted in Table $\mathbf{1}($ Comparison in methodology between conventional and Xylene free method) 
Research Article

Table- 1: Comparison in methodology between conventional and Xylene free method

\begin{tabular}{|c|c|c|c|c|c|}
\hline \multirow[t]{2}{*}{ STEPS } & \multicolumn{2}{|c|}{ CONVENTIONAL METHOD } & \multicolumn{3}{|l|}{ XYLENE FREE METHOD } \\
\hline & Compound & Duration & Compound & Temp & Duration \\
\hline \multirow[t]{6}{*}{ Deparaffinization } & Xylene I & $5 \mathrm{~min}$ & 1.7\% Dil.Dishwash Liquid & $65 / 75 / 90^{\circ} \mathrm{C}$ & $1 \mathrm{~min}$ \\
\hline & Xylene II & $5 \mathrm{~min}$ & 1.7\% Dil.Dishwash Liquid & $65 / 75 / 90^{\circ} \mathrm{C}$ & $1 \mathrm{~min}$ \\
\hline & $90 \%$ alcohol & $5 \min$ & Distilled water & $65 / 75 / 90^{\circ} \mathrm{C}$ & $30 \mathrm{secs}$ \\
\hline & $70 \%$ alcohol & $5 \mathrm{~min}$ & Distilled water & $65 / 75 / 90^{\circ} \mathrm{C}$ & 30 secs \\
\hline & Water wash & $10 \mathrm{~min}$ & Wash in distilled water & $65 / 75 / 90^{\circ} \mathrm{C}$ & 30 secs \\
\hline & & & Wash in distilled water & Room Temp & 30 secs \\
\hline \multirow[t]{2}{*}{ Nuclear Staining } & Harri's hematoxylin & $8 \mathrm{~min}$ & Harri's hematoxylin & Room Temp & $8 \mathrm{~min}$ \\
\hline & Water wash & $2 \min$ & Water wash & & $2 \mathrm{~min}$ \\
\hline Differentiation & $1 \%$ acid alcohol & 1 dip & $1 \%$ acid alcohol & Room Temp & 1 dip \\
\hline Blueing & Water wash & $10 \mathrm{~min}$ & Water wash & Room Temp & $10 \mathrm{~min}$ \\
\hline \multirow[t]{2}{*}{ Cytoplasmic Staining } & $1 \%$ eosin & $1 \mathrm{~min}$ & $1 \%$ eosin & Room Temp & $1 \mathrm{~min}$ \\
\hline & & & Water wash & Room Temp & $1 \mathrm{~min}$ \\
\hline \multirow[t]{4}{*}{ Dehydration } & $90 \%$ alcohol & $30 \mathrm{secs}$ & & & \\
\hline & $70 \%$ alcohol & $30 \mathrm{secs}$ & Oven dry the sections & $60^{\circ} \mathrm{C}$ & $10 \mathrm{~min}$ \\
\hline & Xylene I & $5 \min$ & & & \\
\hline & Xylene II & $5 \mathrm{~min}$ & & & \\
\hline Approximate time & & $70-75$ min & & & $30-35 \mathrm{~min}$ \\
\hline
\end{tabular}

III. Assessment of Stained Tissues: 100 sections were stained with conventional Hematoxylin and Eosin staining and 300 sections were stained with Xylene free method $\left(100\right.$ in $65^{\circ} \mathrm{C}, 100$ in $75^{\circ} \mathrm{C}, 100$ in $\left.90^{\circ} \mathrm{C}\right)$. A randomized set of 400 sections matched into 100 quadruplets were scored and analyzed by a single blinded pathologist. Our study eliminates bias and inter-observer variability that may arise due to analysis using multiple pathologists [2]. Each slide was scored objectively based on a standard scoring system used by Ankle and Joshi 2011 [4], graded based on the parameters of nuclear staining (Adequate $=$ score 1 , Inadequate $=0$ ), cytoplasmic staining (Adequate $=$ score 1 , Inadequate $=$ score 0 ), clarity of staining $($ Present $=$ score 1 , absent $=$ score 0$)$, uniformity of staining $($ Present $=$ score 1 , absent $=$ score 0 ), and crispness of staining $($ Present $=$ score 1 , absent $=$ score 0$)$.

Table- 2: Final Score evaluation and cut-offs

\begin{tabular}{|c|c|}
\hline $0-3$ & Poor; Inadequate for diagnosis \\
\hline $4-5$ & Average \\
\hline $6-8$ & Good; Adequate for diagnosis \\
\hline$>8$ & Excellent; All criteria well seen. \\
\hline
\end{tabular}

\section{Results}

The total scores from various tissue sections were analysed using Wilcoxon Signed Ranks Test to compare staining efficiency of both methods. The advantage with Wilcoxon Signed Rank Test is that it neither depends on the form of the parent distribution nor on its parameters. It does not require any assumptions about the shape of the distribution. For this reason, this test is often used as an alternative to t test whenever the population cannot be assumed to be normally distributed. Even if the normality assumption holds, it has been shown that the efficiency of this test compared to t-test is almost $95 \%$.

According to the test, the Xylene-free sections at $90^{\circ} \mathrm{C}$ were judged to be as good as or better than the matching conventional sections in $76 \%$ of comparisons and poorer in $24 \%$ of the comparisons, which is analogous to results obtained by Falkholm et al [2]. Xylene free sections at $75^{\circ} \mathrm{C}$ and $65^{\circ} \mathrm{C}$ were found to be inferior than the conventional method in $69 \%$ and $80 \%$ of the comparisons respectively. 
Research Article

Comparing numerical scores, the maximum score attainable is 11 . The mean score among the conventional staining group was 8.77 whereas for xylene-free staining group at $90^{\circ} \mathrm{C}$ was 8.3 . The difference between these two groups was not significant $(\mathrm{p}=0.422 ; \mathrm{p}>0.05)$, hence proving no difference in staining characteristics. The mean score for Xylene-free staining group at $65^{\circ} \mathrm{C}$ and $75^{\circ} \mathrm{C}$ are 7.6 and 7.8 and the p value being 0.002 and 0.019 respectively. Thus the difference between lower temperatures and the conventional method is statistically significant from each other.

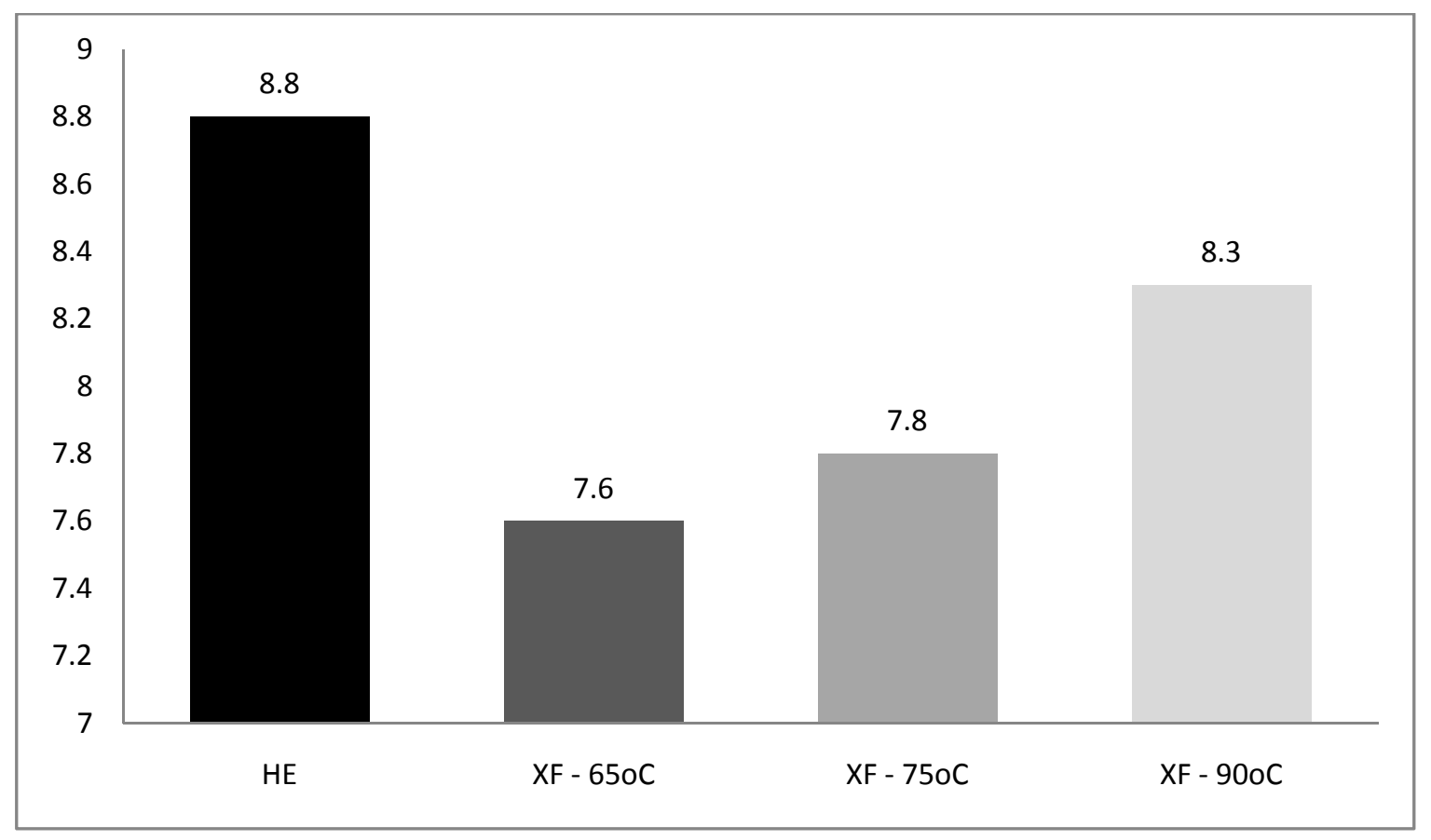

(Figure 1: Comparison of average scores between conventional Hematoxylin and Eosin (HE) method and Xylene free (XF) method at three different temperatures)

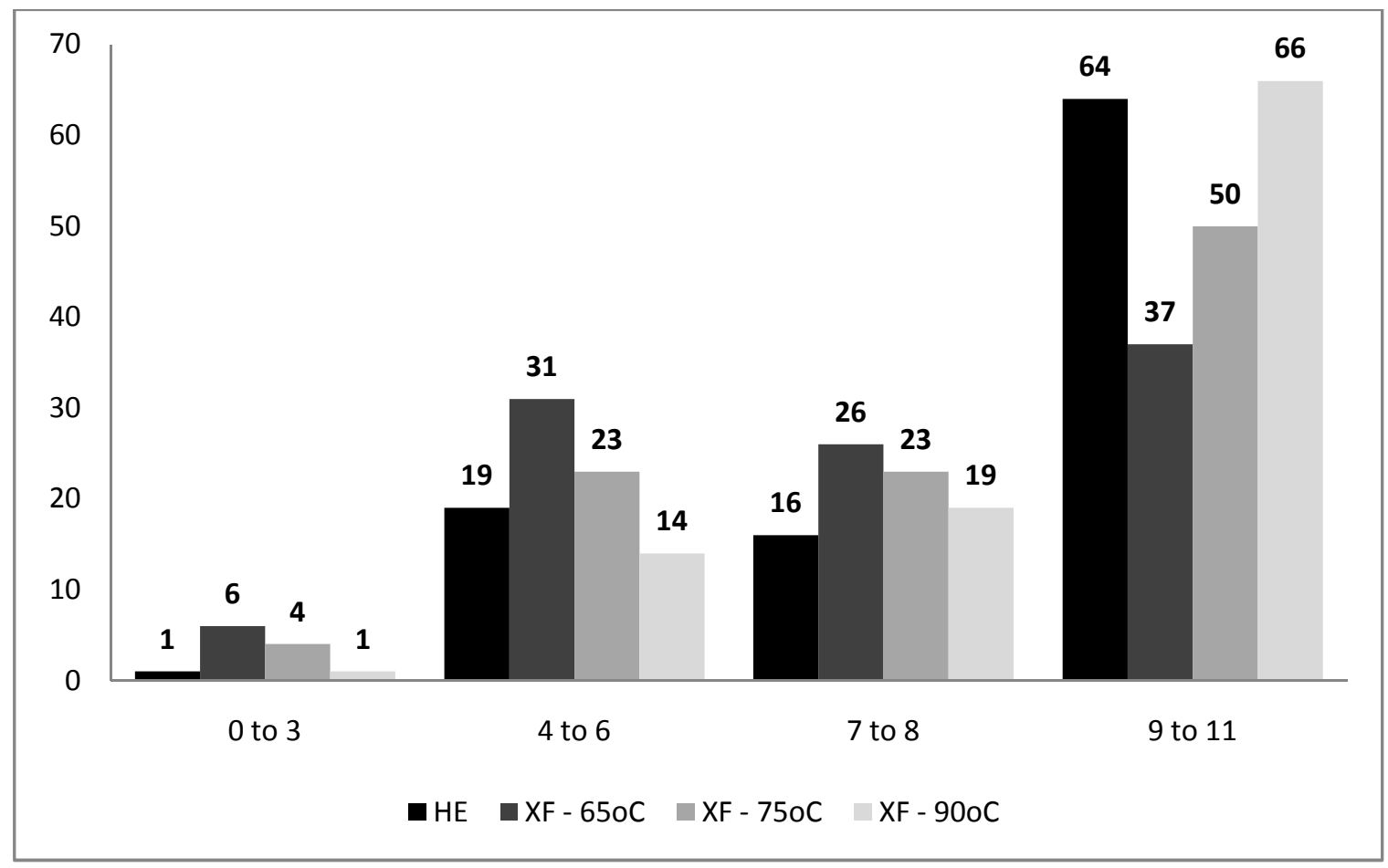

(Figure 2: Average scores by different methods. HE- conventional Hematoxylin and Eosin; XF - Xylene free method) 
Research Article

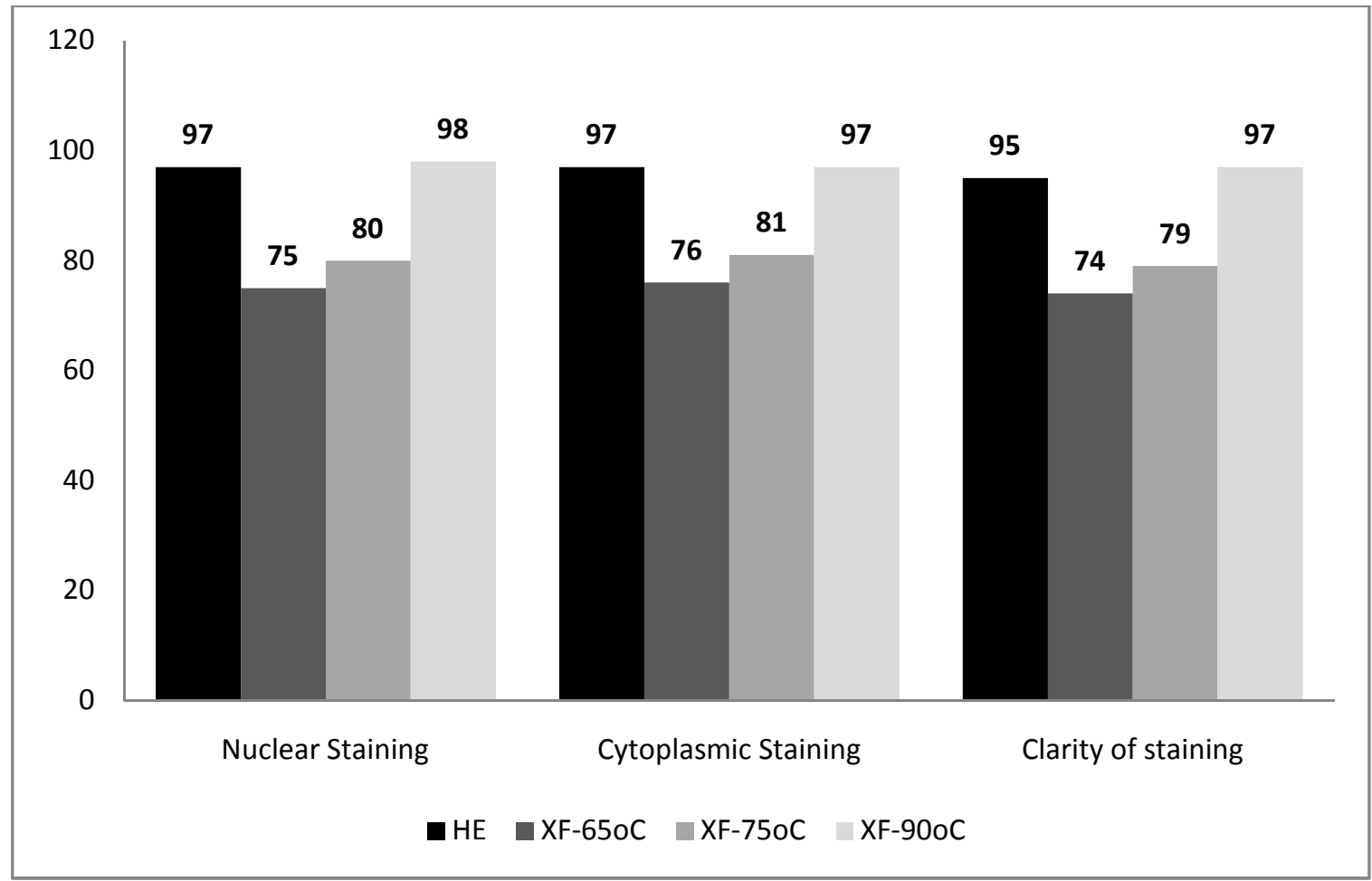

(Figure 3a: Analysis of components of staining between the two methods: HE- conventional Hematoxylin and Eosin method; XF- Xylene free method)

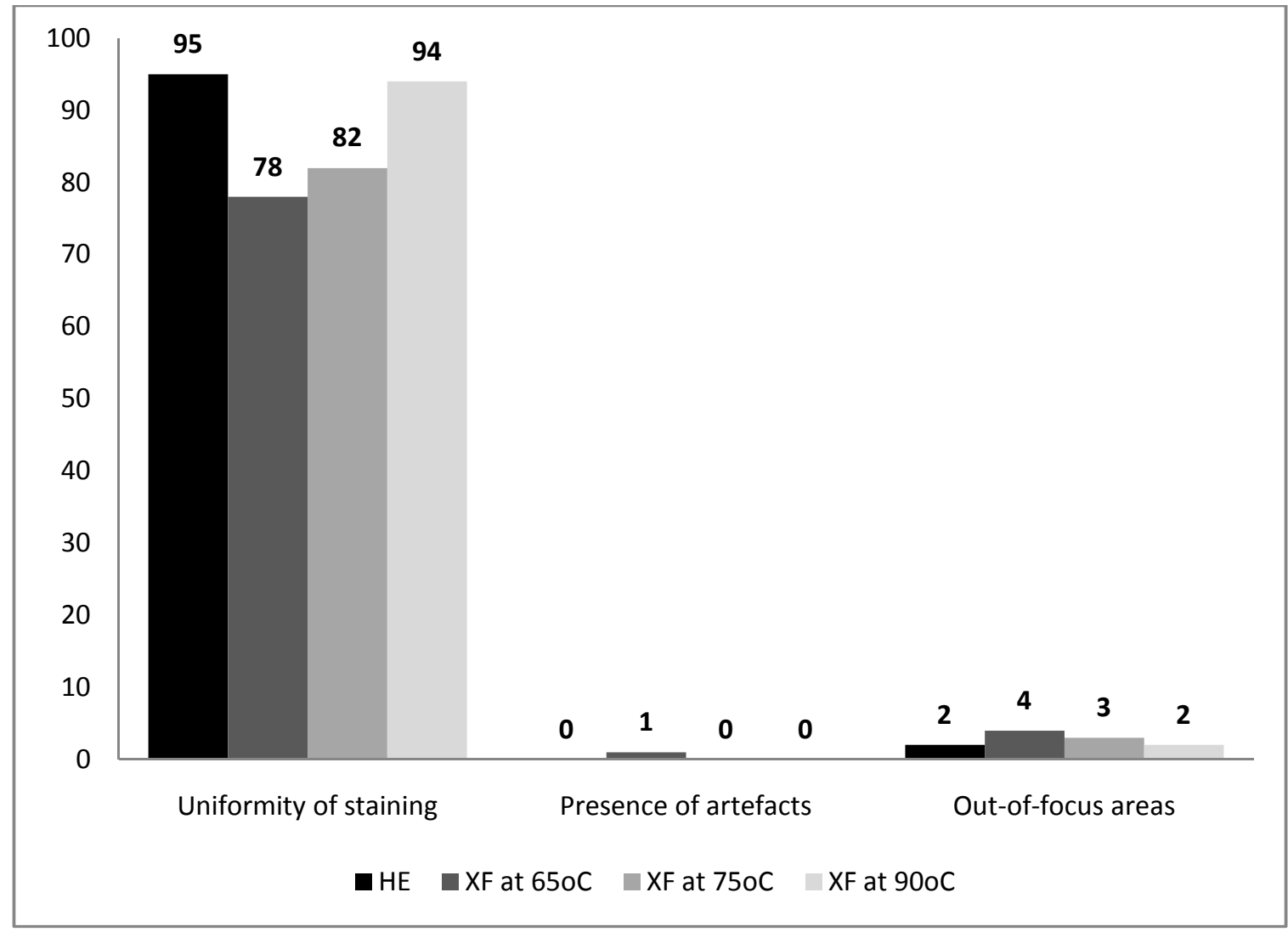

(Figure 3b: Analysis of components of staining between the two methods: HE- conventional Hematoxylin and Eosin method; XF- Xylene free method) 
(Figure 4a-d: Histopathological comparison of epithelial and stromal elements staining (400x) : a-conventional, b:xylene free $90^{\circ} \mathrm{c}, \mathrm{c}$ :xylene free $75^{\circ} \mathrm{c}, \mathrm{d}$ :xylene free $65^{\circ} \mathrm{c}$ )

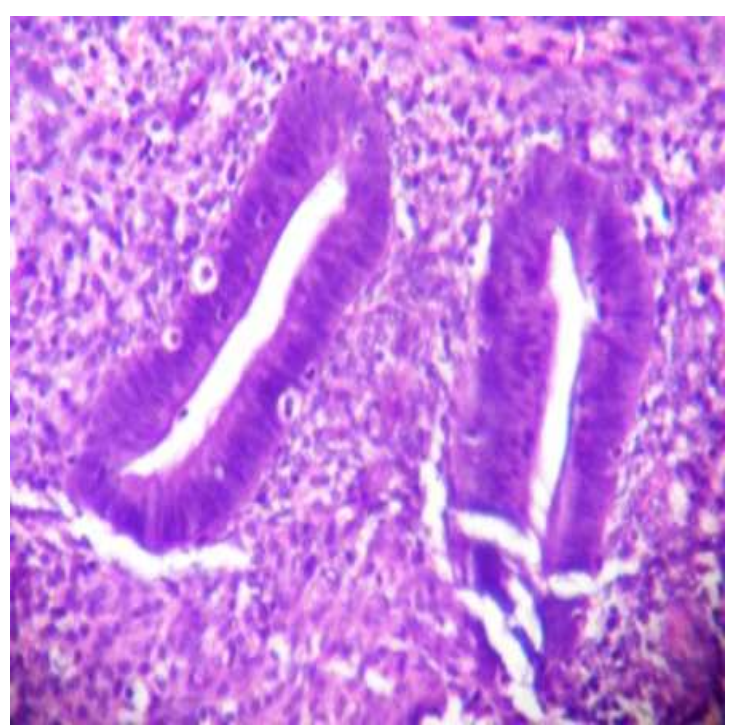

Figure-4a: Hispathological comparison of epithelial and stromal elements staining: conventional H\&E staining 400x

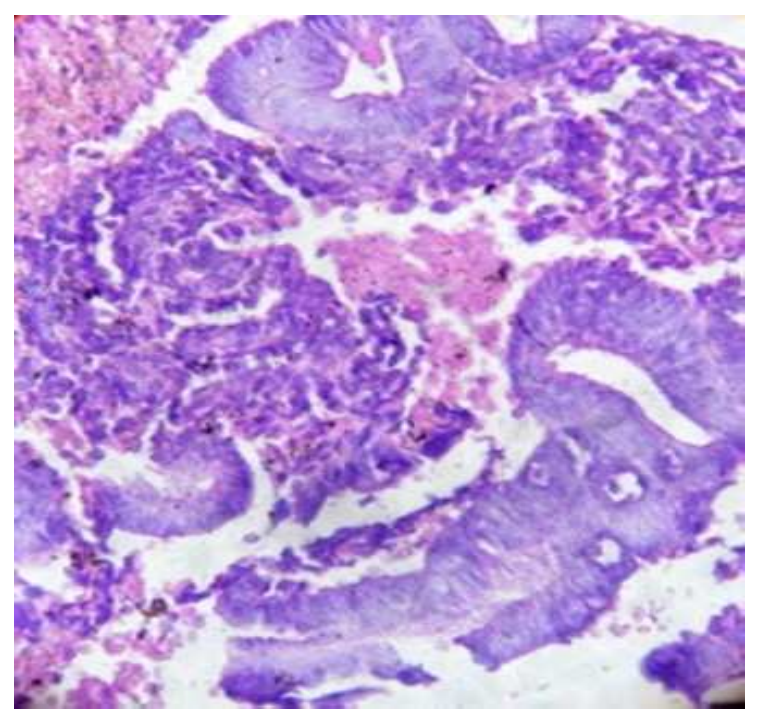

Figure-4 c : Hispathological comparison of epithelial and stromal elements staining : Xylene free $\left(75^{\circ}\right.$ c) $\mathrm{H} \& \mathrm{E}$ staining $400 \mathrm{x}$

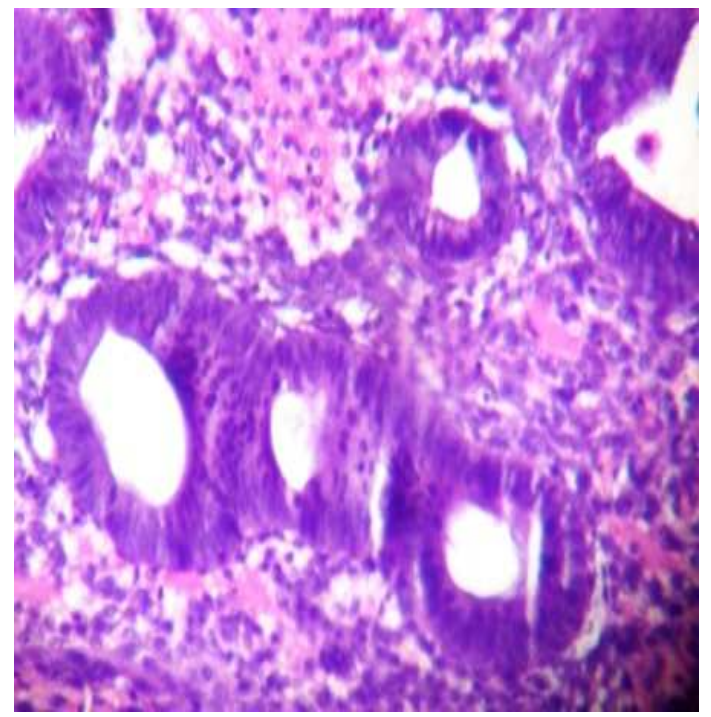

Figure-4b: Hispathological comparison of epithelial and stromal elements staining: Xylene free $\left(90^{\circ} \mathrm{c}\right) \mathrm{H} \& \mathrm{E}$ staining $400 \mathrm{x}$

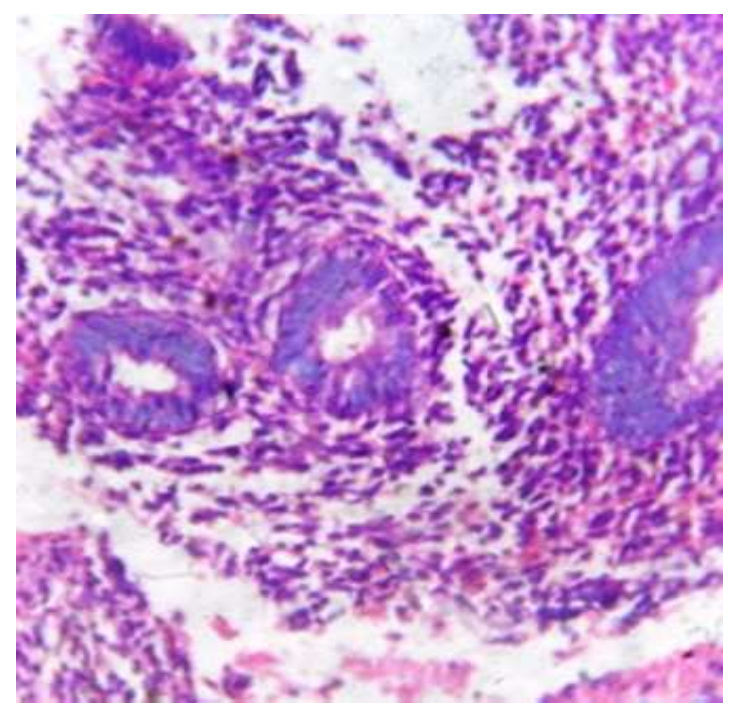

Figure-4 d : Hispathological comparison of epithelial and stromal elements staining : Xylene free $\left(65^{\circ} \mathrm{c}\right) \mathrm{H} \& \mathrm{E}$ staining $400 \mathrm{x}$

A cumulative score of $\geq 6$ was considered to be adequate for diagnosis. The scores for all the components (nuclear and cytoplasmic staining, clarity of staining and uniformity of staining) were equivalent between conventional Hematoxylin \& Eosin and Xylene free method at $90^{\circ} \mathrm{C}$ ( $\mathrm{p}$ value of $0.320,0.456,0.367,0.543$ respectively).

The score for cytoplasmic staining at $75^{\circ} \mathrm{C}$ alone, was equivalent to the conventional Hematoxylin \& Eosin method $(\mathrm{p}=0.070)$.

The scores for rest of the staining components done at $75^{\circ} \mathrm{C}$ and $65^{\circ} \mathrm{C}$ Xylene free method showed statistical significance from the conventional Hematoxylin \& Eosin method and hence is not reliable as an effective substitute and inferior to the 
Research Article

performance at $90^{\circ} \mathrm{C}$. Thus, the new Xylene free method is on par with the conventional Hematoxylin and Eosin method only at $90^{\circ} \mathrm{C}$. (Table 4: Statistical comparisons between conventional Hematoxylin and Eosin method and Xylene free method).

Table-3: Statistical Comparison between conventional hematoxylin and eosin (HE) method and Xylene Free (XF) method

\begin{tabular}{|c|c|c|c|c|c|c|c|}
\hline \multirow[t]{2}{*}{ Staining parameter } & \multirow{2}{*}{$\begin{array}{c}\text { HE } \\
\text { method }\end{array}$} & \multicolumn{3}{|c|}{ XF method } & \multicolumn{3}{|c|}{$P$ value } \\
\hline & & $65^{\circ} \mathrm{C}$ & $75^{\circ} \mathrm{C}$ & $90^{\circ} \mathrm{C}$ & $65^{\circ} \mathrm{C}$ & $75^{\circ} \mathrm{C}$ & $90^{\circ} \mathrm{C}$ \\
\hline $\begin{array}{l}\text { Nuclear Staining } \\
\text { - } \quad \text { Adequate } \\
\text { - } \quad \text { Inadequate }\end{array}$ & $\begin{array}{c}97 \\
3\end{array}$ & $\begin{array}{l}75 \\
25\end{array}$ & $\begin{array}{l}80 \\
20\end{array}$ & $\begin{array}{c}98 \\
2\end{array}$ & $\begin{array}{c}0.002 \\
\mathbf{S}\end{array}$ & $\begin{array}{c}0.003 \\
\mathbf{S}\end{array}$ & $\begin{array}{c}0.320 \\
\text { NS }\end{array}$ \\
\hline $\begin{array}{l}\text { Cytoplasmic Staining } \\
-\quad \text { Adequate } \\
-\quad \text { Inadequate }\end{array}$ & $\begin{array}{c}97 \\
3\end{array}$ & $\begin{array}{l}76 \\
24\end{array}$ & $\begin{array}{l}81 \\
19\end{array}$ & $\begin{array}{c}97 \\
3\end{array}$ & $\begin{array}{c}0.003 \\
\mathbf{S}\end{array}$ & $\begin{array}{c}0.070 \\
\text { NS }\end{array}$ & $\begin{array}{c}0.456 \\
\text { NS }\end{array}$ \\
\hline $\begin{array}{l}\text { Clarity of staining } \\
-\quad \text { Adequate } \\
-\quad \text { Inadequate }\end{array}$ & $\begin{array}{c}95 \\
5\end{array}$ & $\begin{array}{l}74 \\
26\end{array}$ & $\begin{array}{l}79 \\
21\end{array}$ & $\begin{array}{c}97 \\
3\end{array}$ & $\begin{array}{c}0.002 \\
\mathbf{S}\end{array}$ & $\begin{array}{c}0.003 \\
\mathbf{S}\end{array}$ & $\begin{array}{c}0.367 \\
\text { NS }\end{array}$ \\
\hline $\begin{array}{ll}\text { Uniformity of staining } \\
-\quad \text { Adeqaute } \\
-\quad \text { Inadequate }\end{array}$ & $\begin{array}{c}93 \\
7\end{array}$ & $\begin{array}{l}78 \\
22\end{array}$ & $\begin{array}{l}82 \\
18\end{array}$ & $\begin{array}{c}94 \\
6\end{array}$ & $\begin{array}{c}0.001 \\
\mathbf{S}\end{array}$ & $\begin{array}{c}0.001 \\
\mathbf{S}\end{array}$ & $\begin{array}{c}0.543 \\
\text { NS }\end{array}$ \\
\hline
\end{tabular}

S-Significant difference; NS- Non significant difference; Adequate - score $\geq 6$

\section{Discussion}

After the hazardous effects of Xylene became indisputable in the 1970s, many potential substitutes became available in order to make a Xylene-free environment in laboratories, such as limonene reagents, aliphatic hydrocarbons, aromatic hydrocarbons, olive oil, vegetable oils, and mineral oil substitute.

However, these chemicals were used to substitute Xylene as a clearing agent during routine processing, while the exposure and handling of Xylene is maximum during deparaffinization of the tissue sections.

Falkeholm et al., for the first time experimented to use liquid dish washing soap to dewax the tissue sections by eliminating both xylene and alcohol from $\mathrm{H}$ and $\mathrm{E}$ staining procedures [2].

Liquid dish washing detergent effectively deparaffinizes wax through its surfactant action. The surfactant contains molecules with hydrophilic and hydrophobic portions.

They are absorbed into the surface of oil/grease and remove it from the fabric. After removal, the surfactant molecules remain surrounding the oil to prevent its redeposition onto the cleaned surface [5]. There are two categories of detergents: automatic machine dish washing detergents and hand dishwashing detergents. Automatic dishwashing detergents used in automatic dish washers are known to produce skin irritation and are poisonous if swallowed.

Hand dishwashing detergents routinely used in the household are more mild to the skin and if swallowed, may cause mild irritation to the mouth but no dangerous effects [6]. In this technique, since liquid hand dishwashing detergent is highly diluted $(1.7 \%)$ it has less chances of being toxic to histotechnicians when compared to the harmful effects of Xylene.

An important finding observed in our study was Xylene free staining method is highly temperature sensitive. Temperatures less than $90^{\circ} \mathrm{C}$ yielded comparatively lower scores and statistically significant changes when compared with the conventional Hematoxylin \& Eosin staining.

The diluted $1.7 \%$ liquid dish washing liquid has to be maintained strictly at $90^{\circ} \mathrm{C}$. Even the slightest increase in temperature resulted in washing away of the tissue sections from the slide and on the other hand, if the temperature was less than $90^{\circ} \mathrm{C}$ or even if the sections were kept for lesser time than recommended, the sections were not completely deparaffinized leaving 
Research Article

areas of residual wax, resulting in out-of-focus areas. Similar findings were also demonstrated in another study [9].

The important role of temperature is also evident in studies that used dilute lemon water [10] and hot distilled water [11] which had no surfactants and purely relied on high temperature to melt the wax. As the

deparaffinization of wax is highly dependent on temperature, it is important to standardize the wax used in different labs for accurate comparison of results between various studies.

Experiments by Kayser and Bubenzer 1990 [12] and Temel et al 2005 [13] minimized the staining duration to 5-10 minutes by increasing the temperature during deparaffinisation using a simple kitchen microwave and achieved the same results.

With every innovative substitute like the latest cedarwood oil [8] and mineral oil [9], being coupled with high temperature, it makes us doubt whether temperature potentiates or acts as a confounder in all these studies. More standardized large scale studies, involving various types of tissue sections and different types of stain is needed in the future to derive best results and the ideal Xylene substitute.

A minimum of 30 minutes was required for the Xylene free method whereas a minimum of 70 minutes was needed for the corresponding conventional steps.

Thus in concrete terms the saving in time for deparaffinisation and staining using the Xylene free dish washing solution is of significance especially while handling large number of slides like in a tertiary care center.

The only known substance in literature that doesn't require high temperature for effective wax clearing is a mixture of $86 \%$ of white oil No.2 and $14 \%$ of Nheptane. It has a high boiling point $\left(188^{\circ} \mathrm{C}\right)$ and flash point $\left(144^{\circ} \mathrm{C}\right)$ coupled with scentless and decreased volatility [14].

This trial demonstrates that Xylene free histological sections are qualitatively on par with conventional paraffin sections for routine diagnostic work. In view of the savings in time, money and the working environment, the Xylene free method at appropriate temperatures meets today's needs.
It is high time to accept such newer techniques and thereby promoting the elimination of hazardous elements in the routine preparation of slides and thus provide a safe working environment.

Acknowledgements: My sincere thanks to the histotechnicians in the Department of Pathology for their effort in preparing the slides despite their busy clinical work. This wouldn't have been possible if not for their co-operation. I also extend my gratitude to my

Department Chair and the Professors for providing me valuable help in conducting this study.

Declaration of interests: The authors report no conflicts of interest. The authors alone are responsible for the content and writing of this paper.

Funding: Nil, Conflict of interest: None initiated, Permission from IRB: Yes

\section{References}

1. Kandyala R, Raghavendra SPC, Rajasekharan ST. Xylene: An overview of its health hazards and preventive measures. Journal of Oral and Maxillofacial Pathology : JOMFP. 2010;14(1):1-5. doi:10.4103/0973029X.64299.

2. Lars Falkeholm CAG, Anders Magnusson and Eva Möller . Xylene-Free Method for Histological Preparation: A Multicentre Evaluation. Lab. Invest.2001. 81(9):1213-21.

3. Pandey P, Dixit A, Tanwar A, Sharma A, Mittal S. A comparative study to evaluate liquid dish washing soap as an alternative to xylene and alcohol in deparaffinization and hematoxylin and eosin staining. J Lab Physicians 2014;6(2):84-90. doi: 10.4103/09742727.141504.

4. Ankle MR, Joshi PS. A study to evaluate the efficacy of xylene-free hematoxylin and eosin staining procedure as compared to the conventional hematoxylin and eosin staining: An experimental study. J Oral Maxillofac Pathol 2011;15(2):161-7. doi: 10.4103/ 0973-029X.84482.

5. Available from: The essential chemical industry online-materials and methods-surfactants:http://www. essentialchemicalindustry.org/materials-and-

applications /surfactants.html (Accessed february 2016). 


\section{Research Article}

6. Available from: Pesky Pests and Household Hazards:http://www.epa.gov/sites/production/files/2014 -06/documents/lesson2_handout.pdf (Accessed february 2016).

7. Ramulu S, Koneru A, Ravikumar S, Sharma P, Ramesh D, Patil R. Liquid dish washing soap: An excellent substitute for xylene and alcohol in hematoxylin and eosin staining procedure. J Orofac Sci 2012;4(1):37-42. doi: 10.4103/0975-8844.99890.

8. Indu S, Ramesh V, Indu PC, Prashad KV, Premalatha B, Ramadoss K. Comparative efficacy of cedarwood oil and xylene in hematoxylin and eosin staining procedures: An experimental study. J Nat Sc Biol Med 2014;5(2):284-7. doi: 10.4103/0976-9668.136167.

9. B R Premalatha SP, Roopa S Rao, M Indu (2013) Mineral oil--a biofriendly substitute for xylene in deparaffinization: a novel method. J. Contemp. Dent. Pract. 14(2):281-6.

10. Ananthaneni A, Namala S, Guduru VS, et al. Efficacy of $1.5 \%$ Dish Washing Solution and 95\%
Lemon Water in Substituting Perilous Xylene as a Deparaffinizing Agent for Routine $\mathrm{H}$ and E Staining Procedure: A Short Study. Scientifica. 2014;2014:707310. doi:10.1155/2014/707310.

11. Sangeetha R UK, Vidyadevi C, Vijay KJ, Mithilesh M, Premlatha BR (2014) Reagent-free H\&E staining. J. Oral. Maxillofac. Pathol. 18(Suppl 2):S28-S35.

12. Kayser K, Bubenzer J .Microwave-assisted staining procedures in routine histopathology. Histochem. J. $1990: 22(6-7): 365-70$.

13. Temel SG, Noyan S, Cavusoglu I, Kahveci Z . A simple and rapid microwave-assisted hematoxylin and eosin staining method using 1,1,1 trichloroethane as a dewaxing and a clearing agent. Biotech. Histochem. 2005 80(3-4):123-32. doi:10.1080/10520290500303190.

14. Kunhua W, Chuming F, Tao L, et al. A Novel NonToxic Xylene Substitute (SBO) for Histology. African Journal of Traditional, Complementary, and Alternative Medicines. 2012;9(1):43-49.

\section{How to cite this article?}

Gayathri G, Snegha A, Teleflo B. Substitutes for xylene in histopathology and the role of temperature. Trop J Path Micro 2016;2(2):55-63.doi: 10.17511/jopm.2016.i02.04 